\title{
A CRÍTICA NEOATEÍSTA À INFLUÊNCIA DA RELIGIÃO NA POLÍTICA NAS SOCIEDADES CONTEMPORÂNEAS
}

\author{
The Criticism of New Atheists to the influence of Religion on Politics in Contemporary \\ Societies
}

Roney de Seixas Andrade ${ }^{1}$

\section{RESUMO}

A partir da análise do discurso neoateísta em sua crítica à influência da religião na política no âmbito das sociedades contemporâneas em geral e na sociedade estadunidense em particular, o presente artigo visa discutir o estreito relacionamento entre religião e política e as suas permanentes conexões. Diferente daquilo que convencionalmente se pensa, a religião não se reduz a crenças, a ritos e a práticas associadas, antes e primordialmente, a religião é política, isto é, ela está relacionada ao ordenamento do mundo humano-social. Assim sendo, ainda que consideremos que atualmente vivemos em um mundo que "saiu da religião", a religião nunca abandonou completamente a sua vocação política original de ser o fundamento exclusivo do estar junto coletivo e por isso permanece, de certa forma e de diferentes maneiras, presente nos processos políticos mesmo nas sociedades modernas e contemporâneas.

Palavras-chaves: Religião; Política; Ateísmo; Laicidade; Desencantamento do Mundo.

\begin{abstract}
Based on the analysis of discourse of the new atheistics in its critique of the influence of religion in politics in contemporary societies in general and in American society in particular, this article aims to discuss the close relationship between religion and politics and their permanent connections. Different from what is conventionally thought, religion is not limited to beliefs, rituals and practices before and primarily, religion is politics, it is related to the ordering of the human-social world. Therefore, even though we consider that we currently live in a world that "left religion", religion never completely abandoned its original political vocation to be the exclusive foundation of society, remaining, in a certain way and in different ways, present in political processes even in modern and contemporary societies.
\end{abstract}

Keywords: Religion; Politics; Atheism; Secularity; Disenchantment of the World.

\section{INTRODUÇÃO}

Em anos recentes tem sido muito comum a ocorrência de termos religiosos no discurso político-partidário no contexto brasileiro. Desde slogan de campanha - "Brasil acima de tudo,

\footnotetext{
${ }^{1}$ Doutor em Ciência da Religião pelo Programa de Pós-Graduação em Ciência da Religião do Instituto de Ciências Humanas da Universidade Federal de Juiz de Fora (UFJF). E-email: drroneyandrade@gmail.com
} 
Deus acima de todos” - até declarações de ministros do governo - “O Estado é laico, mas esta ministra é terrivelmente cristã” - é possível perceber uma tendência, cada vez mais crescente, da presença da religião não apenas no discurso, mas também nas orientações das políticas públicas e governamentais em nosso país. ${ }^{2}$

Longe de ser uma realidade exclusivamente brasileira, essas “intromissões” da religião na política nas sociedades contemporâneas nas últimas décadas, tem tomado a atenção de diversos analistas e pesquisadores de diferentes partes bem como tem sido motivo de preocupação e crítica de tantos outros. Destaca-se neste contexto os autores que ficaram conhecidos pela mídia em geral como “os novos ateístas”. O discurso desses autores ganhou rápida e forte repercussão após os atentados do 11/9/2001 justamente por denunciar os supostos efeitos deletérios da influência da religião nos processos políticos e de defender a ideia segundo a qual a religião deva ser mantida fora de toda e quaisquer políticas públicas e, se possível, fora de toda experiência no espaço humano-social. ${ }^{3}$

Assim sendo, no presente artigo, pretende-se discutir as relações entre religião e política no início de milênio analisando, ainda que brevemente, (i) o processo da passagem de uma organização heterônoma do ajuntamento humano característico das sociedades primevas para uma organização autônoma das sociedades modernas; (ii) a consolidação da separação jurídicopolítico entre religião e política fundamentado pelo princípio da laicidade no âmbito do Estado Democrático de Direito nas sociedades ocidentais modernas; (iii) as tentativas de recomposição do fundamento heterônomo das sociedades articulado, sobretudo, por movimentos fundamentalistas e neofundamentalistas; (iv) as críticas dos novos ateístas contra a crescente influência da religião na política das sociedades contemporâneas em geral e na sociedade estadunidense em particular. Entendemos que essas análises poderão contribuir para uma reflexão mais acurada de questões fundamentais de um tema relevante e urgente para a nossa época.

\section{I - A DIMENSÃO POLÍTICA DA RELIGIÃo}

\footnotetext{
2 Por exemplo, a intenção do presidente em indicar um ministro "terrivelmente evangélico” para o Supremo Tribunal Federal. Ver: <https://brasil.elpais.com/brasil/2019/07/10/politica/1562786946_406680.html>. Acesso em: 25 jul. 2020.

3 De acordo com Tina Beattie, “logo após os ataques do 11/9 nos Estados Unidos, Dawkins declarou seu compromisso com uma forma mais militante de ateísmo e foi logo acompanhado por um número de outras figuras públicas que interpretaram o 11/9 como um chamado para defender os valores do liberalismo secular ocidental contra o recrudescimento do fanatismo religioso" (2008, loc. 73 of 198).
} 
Um dos traços constitutivos da religião e que a torna de grande relevância para as reflexões e debates acerca da organização humano-social em qualquer momento temporal ou espaço físico-geográfico é a sua dimensão política. Como tem avaliado o filósofo francês Marcel Gauchet, “a religião não se reduz a crenças religiosas e a práticas associadas, como nossa condição de modernos - centrados no presente - tende a nos fazer crer”. Antes, a religião em sua origem e durante milênios esteve associada principalmente a "formas de ordenamento do mundo humano-social, a modos de compreender e de instituir o poder, o vínculo entre os seres, e as comunidades” (GAUCHET, 2005, p. 293-294). ${ }^{4}$

Partindo dessa perspectiva, ou seja, entendendo a religião como dispositivo relacionado inicialmente com a economia do vínculo político e humano-social, não podemos deixar de reconhecer, todavia, que com o desenvolvimento histórico-cultural das comunidades e sociedades, a religião foi paulatinamente perdendo a sua função original de servir como fundamento exclusivo do estar-junto coletivo. Isso significa dizer que estamos presenciando um processo de redução da alteridade do fundamento, isto é, da passagem de uma organização heterônoma do ajuntamento humano para uma organização autônoma das sociedades modernas. Em outras palavras, estamos a assistir a um processo de longa duração da "saída da religião” ou do “desencantamento do mundo". 5

Ainda de acordo com Marcel Gauchet, os mecanismos de operação desse processo de passagem da heteronomia à autonomia, que é o que está em jogo no “desencantamento do mundo", que levou à transição de um mundo movido à religião englobante nas sociedades primais para a autoinstituição religiosa democrática nas sociedades modernas ocorreu, por um

\footnotetext{
${ }^{4}$ Entendendo a religião como dispositivo relacionado inicialmente com a economia do vínculo político e humanosocial é na origem, isto é, na religião das sociedades sem escrita, religião primeira, que se efetuou a despossessão radical, ou seja, se estabeleceu a alteridade integral do fundamento. O religioso nesse contexto encontrava-se em vínculo co-constitutivo com a organização social e a formação da lei. Por isso mesmo, a religião naquele momento foi responsável pela estruturação tanto da ordem coletiva, quanto das existências individuais. A religião naquele momento estruturava um tipo bem determinado de sociedade constituída pela anterioridade e superioridade do princípio da ordem coletiva - recebido e intangível, isto é, heterônomo - sobre a vontade dos indivíduos que ele reúne. Neste sentido, ela era uma sociedade movida à religião englobante (GAUCHET, 2005, p. 41).

${ }^{5}$ Marcel Gauchet considera que vivemos atualmente em um mundo que "saiu da religião", isto é, um mundo em que a religião perdeu "a capacidade de [...] estruturar a política e a sociedade" como um todo, muito embora seja um mundo que permite a "permanência do religioso na ordem da convicção dos indivíduos" (FERRY; GAUCHET, 2008, p. 55). Nesse sentido, continua Gauchet, "fim da religião, como eu creio, deve ser compreendido em termos de fim do papel social da religião. [...] Fim do papel social da religião não significa o fim da crença religiosa, a qual não me parece ter qualquer razão para desaparecer em um horizonte histórico previsível. [...] A saída da religião não significa, mesmo em tendência, o fim da crença religiosa e a desaparição das instituições religiosas. Ela significa uma mudança de estado, uma transformação ocorrida de dentro para fora da própria religião" (GAUCHET, 2004, p. 143, 236)
} 
lado, por três descontinuidades particularmente decisivas: pela emergência do Estado; pela aparição de uma divindade ultra-mundana e uma rejeição religiosa deste mundo em curso - o "período axial"; e, finalmente, pelo movimento interno do cristianismo e, por outro, com o desenvolvimento da própria democracia moderna (GAUCHET, 2005, p. 51). ${ }^{6}$ Como também observa Antoon Braeckman, a história política moderna pode ser entendida como um processo de saída da religião, ou seja, como aos poucos as sociedades abandonaram suas estruturas religiosas (BRAECKMAN, 2008). Assim sendo, enquanto originalmente a religião representava a organização da heteronomia, comparativamente, “a essência do fenômeno democrático moderno, seu caráter excepcional na história humana, que faz dele o começo de outra história, é ruptura com essa ordem heterônoma e advento da política da autonomia”. Nesse contexto, “os homens passam a definir eles próprios, entre si, enquanto indivíduos, a organização de seu mundo comum”, conclui Gauchet (2013, p. 18).

Em consequência desse processo, estamos diante de uma verdadeira reconfiguração do estar-junto coletivo resultante da crise de fundamento das sociedades democráticas contemporâneas. Em nossa opinião, desde o momento em que a religião deixa efetivamente de constituir a fonte das fontes organizadoras das instituições sociopolíticas e culturais e de operar como exclusiva matriz da lei e como fundamento exclusivo da autoridade moral, tornando-se apenas mais uma reserva de sentido, entre outras a fundamentar as convicções últimas dos indivíduos, passamos a vivenciar um definitivo deslocamento do ponto de aplicação do religioso em nossas sociedades. Novamente, como observa o filósofo francês,

\begin{abstract}
A religião cessa inteiramente de ser política - quer dizer, deixa de ser o que ela sempre foi e o que veio sendo cada vez menos, durante os últimos séculos, mas que continuava invencivelmente a ser até data recente, ainda que de um modo sub-reptício. Essa virada modifica de maneira espetacular o lugar do discurso religioso e da crença religiosa na vida social, bem como suas modalidades de manifestação. [...] Ao terminar de desconectar o religioso da ordem política e de sua imemorável função de enquadramento social, essa virada abre uma nova era da religião que ainda não parou de surpreender. Ela modifica os termos e os horizontes do pensável religioso (GAUCHET, 2013, p. 21-22).
\end{abstract}

\footnotetext{
${ }^{6}$ Segundo Marcel Gauchet, "a questão das relações entre religião e política encontra-se no centro da gênese das democracias. Antes de ser um fenômeno social e político, a democracia dos modernos é um fato metafísico. Recolocada no contexto de longa duração das sociedades humanas, a democracia é a expressão por excelência da saída da religião. Ela é, na sua essência, uma ruptura com o modo de estruturação religiosa característico das sociedades humanas aténs da nossa. A democracia é o poder dos homens substituindo a ordem definida pelos deuses ou exigida por Deus” (GAUCHET, 2013, p. 18).
} 


\title{
II - RELIGIÃO E POLÍTICA NA MODERNIDADE: O PRINCÍPIO DA LAICIDADE.
}

No plano político das sociedades modernas ocidentais, essa passagem da organização heterônoma para uma organização autônoma das sociedades, ou seja, esse deslocamento do ponto de aplicação da religião que culminou com a separação jurídico-político entre religião e política, ou mesmo, entre Estado e Igreja, tem sido descrita pelo conceito de "laicidade".

\section{A Declaração Internacional sobre a Laicidade no Século XXI, postula que}

\begin{abstract}
Um processo de laicização emerge quando o Estado não se encontra mais legitimado por uma religião ou por uma família de pensamento particular e quando o conjunto dos cidadãos pode deliberar pacificamente, em igualdade de direitos e dignidade, para exercer sua soberania no exercício do poder político. [...] Elementos de laicidade aparecem necessariamente em toda sociedade que quer harmonizar as relações sociais marcadas por interesses e concepções morais ou religiosas plurais (2006, p. 253). ${ }^{8}$
\end{abstract}

De acordo com Jean-Paul Willaime, Laïcité se refere ao princípio geral da neutralidade do aparato público em relação a qualquer e a todo sistema de crenças e de visões de mundo. Isto incluiria o princípio da respectiva independência entre governo e religião. No plano filosófico, laïcité se refere ao secular, ao não-religioso, ou seja, a uma visão de mundo concebida como uma alternativa às crenças religiosas. Assim, considerando os atributos político e filosófico, percebemos em consonância com Willaime, que o termo laïcité implica por um lado uma dimensão de neutralidade do Estado, i.e., "secularismo como um princípio geral de relações entre o Estado e as religiões nas democracias pluralistas respeitando a liberdade de consciência, de pensamento, de religião, bem como tudo o mais que a liberdade implica”; por outro lado, laïcité implica uma visão não religiosa de mundo, i.e., “secularismo como um conceito filosófico que é agnóstico e possui um livre pensar, promovendo uma visão secular ou secularista do homem e do mundo, como uma alternativa para as cosmovisões religiosas" (WILLAIME, 2014, p. 65).

\footnotetext{
${ }^{7}$ No escopo de suas análises acerca do processo de desencantamento do mundo, ao considera-la em sua dimensão mais profunda como a transmutação do antigo elemento religioso em algo distinto da religião, Marcel Gauchet afirma rejeitar "as categorias de 'laicização' e 'secularização', porque não dão conta do sentido último do processo". Ele ainda enfatiza que "ambas noções têm origem no meio eclesiástico. Surgem do esforço da instituição para definir-se por contraste. Designa o que não faz parte da Igreja aquilo que escapa a sua jurisdição" (2003, p. 24).

${ }^{8}$ Na avaliação de Wilmar do Valle Barbosa, [...] para os signatários desta Declaração, a laicidade define-se com base em três princípios: respeito à liberdade de consciência e de sua prática individual e coletiva; autonomia do político e da sociedade civil com relação às normas religiosas e filosóficas particulares; não discriminação direta ou indireta de seres humanos (2013, p. 86).
} 
Já na avaliação do filósofo espanhol Henri Peña-Ruiz, o termo "laicismo” pode ser conceituado como "a doutrina que defende a independência do homem ou da sociedade, e mais particularmente do Estado, de toda influência eclesiástica ou religiosa” (2001, p. 37-38). Portanto, um dos vetores essenciais da laicidade é a separação definitiva entre Estado e Igreja. Por isso, erroneamente, alguns afirmam que a laicidade é antirreligião, enquanto na realidade a laicidade defende o tratamento igual a todas as crenças e o livre exercício de culto. O que há de fato no pensamento laico é a defesa da liberdade de consciência e da neutralidade confessional do poder público, ou seja, no bojo da laicidade reside uma atitude anticlerical e não antirreligião. Ainda de acordo com Peña-Ruiz, “a separação do Estado e de qualquer igreja não significa luta contra a religião, mas sim, simplesmente, vocação para a universalidade, e ao que é comum a todos os homens para além das suas diferenças” (PEÑA-RUIZ, 2000).

De fato, a laicidade não se caracteriza por uma postura antirreligião. Ela é antes, caracterizada por uma postura anticlerical, isto é, ela se coloca em oposição a tentativa de influência ou captura do poder temporal pelo clero. De acordo com o filósofo espanhol,

O laicismo não é, em si mesmo, antirreligioso ao que ele se opõe, é ao entrincheiramento da religião na política, sua invasão no domínio público relacionadas ao cidadão, sem mais, independentemente de suas crenças. Ali onde essa vontade de apoderar-se do Estado (ou de permanecer nele) se manifesta em um clero, ali onde há clericalismo, o laicismo é forçosamente anticlerical, como a democracia é forçosamente antifascista ali onde existem grupos que pretendem impor um Estado totalitário. (PEÑA-RUIZ, 2001, p. 37-38).

\section{III - RELIGIÃO E POLÍTICA NA MODERNIDADE: TENTATIVAS DE RETORNO AO TEOLÓGICO-POLÍTICO.}

Muito embora a laicidade como princípio e ideal ocupe lugar de destaque e de grande importância em nossas sociedades modernas e contemporâneas, garantindo no plano jurídicopolítico a neutralidade axiológica do Estado e a liberdade e pluralidade religiosa fundamentais para a sustentação do Estado Democrático de Direito, o fato é que, de certa forma e de diferentes maneiras, a religião nunca abandonou completamente a sua vocação política original de ser o fundamento exclusivo do estar junto coletivo.

Um exemplo paradigmático do persistente papel político da religião nas sociedades ocidentais contemporâneas que merece atenção neste artigo é o caso dos Estados Unidos. 
Pelo o que podemos verificar nas fontes bibliográficas disponíveis e mesmo por nossas impressões in loco, a religião tem desempenhado um papel político fundamental na sociedade estadunidense. Segundo alguns analistas, essa presença da religião foi revigorada - contra todas as previsões das teorias secularistas modernas - a partir de meados da década de 1970 por aquilo que ficou conhecido como "ressurgimento fundamentalista”, ou como "neofundamentalismo". 9

Como sabemos, nas últimas décadas tem havido uma reflexão, por uma parte significativa da comunidade evangélica norte-americana sobre sua percepção de que a América se encontra em uma crise moral e em um processo de declínio espiritual, isto é, percepção da emergência de um contexto que alguns autores têm denominado de pós-cristianismo. ${ }^{10}$ Nesse contexto, os evangélicos assumem-se como atores religiosos moralmente privilegiados e acreditam estar defendendo os Estados Unidos contra o ateísmo e contra os valores do humanismo secular quando postulam a manutenção stricto sensu do que entendem ser o legado cristão. Além disso, teologicamente fundamentados numa concepção segundo a qual os cristãos têm obrigação moral de assumir o controle político da sociedade, dado o seu relacionamento com Deus, “alguns cristãos evangélico deliberaram recriar o Partido Republicano para promulgar sua visão de mundo estruturada pela lógica da guerra cultural contra o aborto, a evolução, o homossexualismo, o multiculturalismo, a pornografia e a separação da igreja e estado” (HALEY; DAVIS, 2008, p. 70).

\footnotetext{
${ }^{9}$ Segundo George Marsden, muito embora seja possível identificar já em 1968 versões cristianizadas da retórica política própria da era Nixon, veiculadas, sobretudo, por intermédio da revista Christianity Today e de seu editor Harold Lindsell, é em meados da década de 1970 que o evangelicalismo norte-americano ressurge com destaque na vida pública norte-americana. Nesse contexto, ele produziu desdobramentos que brilharam mais intensamente do que o fragmentado fundamentalismo dos primeiros cinquenta anos do séc. XX, que a despeito da sua própria fragmentação proporcionou uma espécie de "centro". Um desses desdobramentos foi a criação da assim chamada Maioria Moral, produto da atividade de um segmento evangélico fundamentalista separatista liderado por Jerry Falwell. Esse pastor batista foi de fato um reformador do fundamentalismo cristão norte-americano, assumindo de certa forma um papel paralelo ao que tiveram Billy Graham e seus novos grupos evangélicos na década de 1950. Assim sendo, "neofundamentalismo é um termo apropriado para qualificar o movimento inaugurado por Falwell. Mantendo a herança fundamentalista do separatismo eclesiástico (e, portanto, permanecendo distante de Graham), Falwell tentou trazer de volta os fundamentalistas, que desde a década de 1930 vivam separados em seus enclaves para os centros da vida americana, especialmente através da ação política e da filiação ao Partido Republicano, pois política significa aliança [...]. Assim sendo enquanto o 'establishment' evangélico encontrava-se imobilizado por uma divisão interna, Falwell assumiu o programa de sua ala direita e mobilizou muitos americanos com determinação fundamentalista” (MARSDEN, 1991, p. 76).

${ }^{10}$ O termo "pós-cristão" (Post-Christian) tem sido usado para designar também o declínio geral do cristianismo, principalmente na Europa, nos últimos cinquenta anos. Um "mundo pós-cristão" é aquele onde o cristianismo não constitui mais uma "religião englobante", isto é, um contexto onde os valores morais, culturais e a própria concepção da realidade não são mais debitárias fundamentalmente do ensinamento religioso cristão. A cerca do termo pós-cristianismo cf. HEELAS; MARTIN, 1999, p. 218.
} 
A partir de 1970, assistimos, então, à emergência da estratégia de conquista do mundo, ou seja, a tentativa de assumir o controle daquelas estruturas da sociedade que na percepção dos fundamentalistas dão suporte e fôlego aos seus inimigos, visando com isto alijá-los definitivamente do poder. No caso do fundamentalismo protestante nos Estados Unidos, dentre os principais inimigos está o próprio Estado, enquanto instituição secular e religiosamente neutra, que na avaliação fundamentalista, de acordo com Almond, Sivan e Appleby,

penetra, através de sua burocracia racionalizada, em todas as esferas da vida pela introdução de uma educação secular e/ou pela restrição à religião ou práticas religiosas nas escolas, e pela permissão ou encorajamento de práticas pecaminosas como o divórcio, sexo fora do casamento, homossexualidade, aborto etc. (1991, p. 411).

Assim sendo, os fundamentalistas, que haviam se isolado após o caso Scopes, deixando os que eles chamavam pejorativamente de humanistas à vontade para promover a causa secularista em nome da liberdade, voltam com toda a carga à cena pública em meados dos anos de 1970 para defender a “moralidade” e a “decência” para o bem dos EUA. As palavras de Hal Lindsey definem bem esta nova postura:

Devemos assumir ativamente nossa responsabilidade de cidadãos e de membros da família de Deus. Precisamos nos mobilizar para eleger representantes que não só reflitam no governo a moralidade da Bíblia, como também elaborem políticas interna e externa que protejam nosso país e nosso estilo de vida (LINDSEY, 1980, p. 157). ${ }^{11}$

Exemplo marcante desse processo de modificação de estratégia no âmbito do movimento fundamentalista norte-americano foi a fundação da organização denominada Maioria Moral (Moral Majority). Criada pelo reverendo Jerry Falwell em junho de 1979, em Washington, esta organização supraconfessional visava agrupar todos aqueles que ansiavam pela edificação de um Estado cuja ação política fosse teologicamente fundada, isto é, fosse “cristã”. Assim sendo, o objetivo de Falwell foi o de "instigar os fundamentalistas protestantes a se envolverem na política e a contestarem a legislação estadual e federal que impunha uma

\footnotetext{
${ }^{11}$ Muitos secularistas, teólogos liberais e até mesmo setores conservadores do evangelismo protestante, foram surpreendidos com o ressurgimento fundamentalista. Muitos deles achavam que a religião jamais voltaria a ocupar um lugar de destaque no cenário político e na esfera pública norte-americana. Porém, a década de 1970 assistiu justamente a uma explosão da fé militante (ARMSTRONG, 2009, p. 374).
} 
agenda 'humanista secular'” (ARMSTRONG, 2009, p. 374-375). ${ }^{12}$ Segundo o seu fundador essa organização teria como objetivo,

\begin{abstract}
Exercer uma significativa influência no direcionamento espiritual e moral de nossa nação: (a) pela mobilização das bases da moral na América numa voz clara e efetiva; (b) informando à maioria moral sobre o que está acontecendo pelas suas costas em Washington e nas assembleias legislativas estaduais em todo o país; (c) através da realização intensiva de lobby no Congresso para derrotar a ala esquerda, os projetos de lei de bem-estar social que irão mais adiante corroer nossa preciosa liberdade; (d) Impulsionar uma legislação positiva através, por exemplo, do estabelecimento da Agência de Proteção da Família, que assegurará uma América forte e resistente; e (e) auxiliar a maioria moral a combater, nas comunidades locais, a pornografia, a homossexualidade, a defesa da imoralidade em livros escolares, e outros problemas enfrentados por todos e por cada um de nós (FALWELL, 1980, p. 227).
\end{abstract}

Conforme destaca Kjell Lejon, Falwell expressava sua interpretação fundamentalista da mensagem bíblica e do seu possível impacto na política nos Estados Unidos através de seu então famoso programa de TV, The Old-Time Gospel Hour (transmitido para 34 milhões de lares a cada domingo à noite), da Moral Majority Report (uma revista mensal) e de seus livros, tais como Listen America! (LEJON, 1988, p. 25) ${ }^{13}$. No calor de sua militância à frente da Maioria Moral, Falwell declarou que o movimento fundamentalista “é composto por milhões de americanos que estão profundamente preocupados em relação ao fundamento em que nossa nação está firmada”. Para ele, os membros deste movimento são:

\begin{abstract}
Católicos, judeus, protestantes, mórmons, fundamentalistas - negros e brancos agricultores, donas de casa, empresários e empresárias. Nós somos americanos de todas as esferas da vida unidos por uma preocupação central: para servir como um grupo de interesse especial proporcionando uma voz para um retorno à sanidade moral dos Estados Unidos da América. A Maioria Moral é uma organização política e não se baseia em considerações teológicas [...] Nós somos americanos que estamos orgulhosos de sermos conservadores em nossa abordagem moral, social e em nossas preocupações políticas (DOBSON; FALWELL; HINDSON, 1986, p. 188).
\end{abstract}

Como podemos notar, o objetivo declarado da organização fundada por Falwell era combater política e ideologicamente o establishment liberal e lutar por certo futuro para os Estados Unidos, pois, no entender de seus integrantes, os americanos deviam constituir uma civilização e uma política determinada pela Bíblia. Assim sendo, “Os fundamentalistas agrupados no que logo se tornaria conhecida como a Nova Direita Cristã (ou Nova Direita

\footnotetext{
12 Sobre o relacionamento dos neofundamentalistas com a “agenda do humanismo secular” ver também: HART, 2002, p. 115-171.

${ }^{13}$ Os dados de audiência do programa de Jerry Falwell encontram-se na revista Time, sept.2, 1985, p. 30.
} 
Religiosa) partiram para a ofensiva depois de cinquenta anos de quietismo” (ARMSTRONG, 2009, p. 416). ${ }^{14}$

Como pudemos verificar esses operadores da assim chamada New Christian Right assumiram uma compreensão segundo a qual os Estados Unidos haviam perdido o caminho da vida moral quando, por influência de sua poderosa elite liberal, deu mais importância à manutenção de uma ordem política na América, baseada numa perspectiva secular (laica), multicultural e socializante do que à manutenção da fidelidade às suas raízes judaico-cristãs (HALEY; DAVIS, 2008, p. 69-70).

De fato, Frank Lambert observa que para alguns, a Nova Direita Cristã está envolvida justamente em uma guerra de culturas colocando cristãos contra humanistas. Esse posicionamento pode ser visto, por exemplo, em Gary DeMar, presidente da American Vision, uma organização cujo lema é “equipar e potencializar cristãos para restaurar a Fundação Bíblica Americana”. Assim como Jerry Falwell e Pat Robertson, ele e seus seguidores acreditam que a herança cristã da América está enraizada em verdades bíblicas, verdades que os humanistas têm deixado de lado. Baseado nesta percepção, ele emoldurou seu discurso da seguinte maneira:

A questão crítica dos nossos dias é o relacionamento de Cristo e Sua Palavra com o nosso sistema político e legal nos Estados Unidos. Quem tem jurisdição sobre todos os aspectos da sociedade americana, Jesus Cristo ou o Estado? Esta deve ser uma nação cristã ou uma nação humanista? (Apud. LAMBERT, 2008, p. 186).

Esta posição em prol da influência religiosa cristã na política dos Estados Unidos tem sido denominada por alguns autores como uma posição “teocrática”. Por exemplo, Michele Goldberg utiliza o termo “teocracia” para referir-se ao atual estado do pensamento cristão norteamericano. No seu entendimento este pensamento traz consigo a convicção de que “o

\footnotetext{
${ }^{14}$ Outro exemplo marcante dessa nova orientação do fundamentalismo norte-americano foi a fundação, em 1989, da Coalizão Cristã (Christian Coalition) pelo televengelista e presidenciável Pat Robertson. De acordo com Frank Lambert, a Coalizão Cristã emergiu como uma poderosa máquina política na era eletrônica, através de seu efetivo uso da internet, bem como da televisão. O objetivo de seu fundador ao organizá-la foi o de implementar assuntos morais numa perspectiva conservadora na agenda pública nacional bem como o de eleger candidatos conservadores para cargos em todos os níveis, desde os conselhos escolares locais à presidência da república federativa norte-americana (LAMBERT, 2006, p. 295). Na mesma direção do discurso de Pat Robertson, mas num tom ainda mais incisivo, Randall Terry, chefe do grupo antiaborto Operação Resgate (Operation Rescue), denunciou aqueles que comemoraram o pluralismo religioso na nação. Ao dirigir-se aos seus seguidores em 1993, Terry declarou: "Eu quero apenas que você deixe uma onda de intolerância cair sobre você. Sim, o ódio é bom... Nosso objetivo é uma nação cristã. Temos o dever bíblico, fomos chamados por Deus, para conquistar este país. Nós não queremos tempo balanceado (equal-time). Nós não queremos pluralismo” (In: CAYLOR, 1993).
} 
verdadeiro cristianismo deve governar todos os aspectos da vida pública e privada, e que tudo - política, ciência, cultura e relacionamentos - deve ser compreendido conforme ordenados na Escritura” (GOLDBERG, 2006, p. 5). Para Bem Stahlberg, “os críticos da teocracia mostram como a divisão formal entre igreja e estado na verdade permite à igreja ter uma influência significativa sobre o estado” (STAHLBERG, 2008, p. 111). Muito embora o muro de separação entre religião e política tenha definido os papéis de cada uma destas instâncias no cenário da formação da república nos Estados Unidos, isto não significou o afastamento de ações coordenadas de comunidades religiosas no âmbito das discussões sobre políticas públicas daquele país, sobretudo das ações de certas comunidades que seguem a perspectiva fundamentalista.

De acordo com Benson e Heltzel, a presença cultural e política do fundamentalismo e o impacto mesmo dos eventos de 11/09/2001 resultaram em mudanças na própria retórica política das ocupantes da Casa Branca. Coube ao ex-presidente George W. Bush transformar esta instituição enquanto um bully pulpit em um púlpito tout court, repleto de "chamadas” e “missões” e “charges to keep” acerca do papel dos EUA no mundo. De acordo com esses autores, George Bush estava convencido que os americanos estão engajados em uma batalha moral entre o bem e o mal e que aqueles que não estão com eles estão do lado errado neste confronto divino (2008, p. 29). Na avaliação desses autores esta teologia adotada por Bush é uma má teologia (2008, p. 30). No entanto, ela é a mesma que alimenta a imaginação religiosopolítica de muitos fundamentalistas e neofundamentalistas, norte-americanos ou não.

O fato, no entanto, é que após os referidos ataques, a Casa Branca cuidadosamente produziu um roteirizado serviço religioso que levou o referido ex-presidente a declarar guerra ao terrorismo do púlpito mesmo da National Cathedral. Com a maior parte dos membros do gabinete e do Congresso presentes, juntamente com os líderes religiosos do país, o então presidente George Bush enfatizou - em uma liturgia televisionada nacionalmente a qual foi finalizada com a execução do Battle Hymn of the Republic - o caráter divino da nova guerra dos EUA contra o terrorismo, declarando que “nossa responsabilidade para a história já está clara: responder esses ataques e livrar o mundo do mal” (BENSON; HELTZEL, 2008, p. 30).

Neste mesmo tom, falando no primeiro aniversário do 11/09, o Presidente Bush finalizou seu discurso à nação na Ellis Island com as seguintes palavras: 
Amanhã é 12 de Setembro. Um marco é passado, e uma missão continua. Seja confiante. Nosso país é forte. A nossa causa é ainda maior do que o nosso país. A nossa causa é da dignidade humana; liberdade guiada pela consciência e guardada pela paz. Este ideal da América é a esperança de toda a humanidade. Essa esperança atraiu milhões para este porto. Essa esperança ainda ilumina o nosso caminho. E a luz resplandece nas trevas. E a escuridão não prevalecerá contra ela. Que Deus abençoe a América (BUSH, 2002).

Avaliando a postura adotada pelo Presidente George W. Bush, após os atentados do 11 de Setembro, 2001, o teólogo Jim Wallis afirma que "a política externa dos Estados Unidos é mais do que presunçosa, ela é teologicamente arrogante; ela é não apenas unilateral, mas perigosamente messiânica; não é apenas arrogante, mas estabelecida na fronteira da idolatria e da blasfêmia”. Em sua opinião, a fé pessoal de George Bush o levou a uma profunda autoconfiança em sua 'missão' de lutar contra o ‘eixo do mal’, em relação ao seu “chamado” para ser o comandante-chefe na guerra contra o terrorismo, e em relação a sua definição da responsabilidade da América para defender a todos e de ser a esperança de toda a humanidade. Em sua avaliação, portanto, essa postura adotada pelo Presidente se constituiu "uma perigosa mistura de uma má política externa e de uma má teologia” (WALLIS, 2008, p. 31).

Entretanto, Wallis acredita que a resposta a essa má teologia praticada por George Bush não seja o secularismo, mas sim uma boa teologia. Assim sendo, "a resposta a má teologia não é o secularismo, mas, ao contrário, uma boa teologia”. Em sua opinião, portanto, persiste a concepção segundo a qual não é sempre errado invocar o nome de Deus e que, as alegações feitas pela religião na vida pública da nação têm o seu próprio lugar. Assim, considerando a influência positiva da liderança profética e moral de Martin Luther King Jr., Desmond Tutu e Oscar Romero, Wallis avalia que,

Em nossa própria história Americana, a religião tem sempre sido levada para a vida pública em dois muito diferentes caminhos. Um, invoca o nome de Deus e a fé a fim de nos considerar responsáveis em relação às intenções de Deus - chama-nos à justiça, a compaixão, a humildade, ao arrependimento e a reconciliação. Abraham Lincoln, Thomas Jefferson, e Martin Luther King Jr. talvez sejam os melhores exemplos deste caminho. Lincoln frequentemente usava a linguagem das Escrituras, mas no sentido de chamar ambos os lados na Guerra Civil para a contrição e para o arrependimento. Jefferson por sua vez disse, "Eu tremo para meu país quando eu reflito que Deus é justo, que sua justiça não pode dormir para sempre”. O segundo caminho invoca as bênçãos de Deus em nossas atividades, agendas e propósitos. Muitos presidentes e líderes políticos têm usado a linguagem religiosa desta forma, e George W. Bush foi vítima dessa mesma tentação (WALLIS, 2008, p. 31-32).

\section{IV - RELIGIÃO E POLÍTICA: A CRÍTICA DOS NOVOS ATEÍSTAS.}


O discurso neoateísta emerge sob os impactos traumáticos do 11 de setembro de 2001, tornando-se conhecido pela opinião pública norte-americana sobretudo a partir da publicação de cinco polêmicos best-sellers: The End of Faith (2004) e Letter to a Christian Nation (2006), escrito pelo neurocientista Sam Harris; Breaking the Spell (2006), do filósofo Daniel Dennett; The God Delusion (2006), elaborado pelo reconhecido biólogo evolucionista Richard Dawkins; God is not Great (2007), de autoria do jornalista político Christopher Hitchens. Nessas obras estão expostas, principalmente, a crítica desses autores contra a crescente influência da religião na política das sociedades contemporâneas em geral e na sociedade estadunidense em particular.

De fato, o próprio Richard Dawkins, deixa claro que, os ataques do 11 de setembro, serviram para mostrar que as coisas estão diferentes no mundo, e que por isso mesmo aqueles que por anos têm educadamente escondido seu desprezo pela perigosa ilusão coletiva da religião precisam se levantar e proclamar, denunciando a real ameaça que a religião mesma oferece ao mundo (DAWKINS, 2001).

Sem dúvida, o mesmo sentimento pelo qual Dawkins foi tomado após o 11 de setembro, tomou conta também de tantos outros intelectuais tais como Sam Harris, Christopher Hitchens e Daniel Dennett, notoriamente, levando-os a produzir um discurso veemente contra a religião talvez nunca visto na história norte-americana. E não apenas isso. Como destaca Hebert London, "muito do que os americanos são e serão como povo foi determinado pelos ataques terroristas do 11 de setembro” (LONDON, 2008, p. 81). Dentro dessa perspectiva podese dizer que o discurso neoateísta não é meramente uma crítica à religião. Na realidade ele constitui também uma tentativa de fornecer subsídios ideológicos para a formação de uma possível nova identidade para os EUA, identidade baseada, desta feita, numa completa denegação da religião como reserva de sentido válida.

Assim sendo, muito embora o discurso neoateísta se constitua por sua crítica à religião em sua presença global e às crenças e perspectivas éticas, políticas e morais a ela associadas como um todo, independentemente de sua tradição, devemos nos atentar para o fato que, diferente dos ateísmos do passado, este discurso é elaborado num contexto específico, tendo como "centro gravitacional” os ataques do 11 de Setembro de 2001. Em outras palavras, o discurso neoateísta emerge como uma crítica ao motor religioso mesmo, o qual, por sua vez, 
tem movido a política, a cultura e a sociedade dos Estados Unidos da América, uma nação paradoxalmente secular e religiosa ao mesmo tempo.

O contexto de surgimento do movimento neoateísta faz com que percebamos que seu discurso constitui uma resposta a um momento político-cultural mais geral, ou seja, uma resposta ao retorno do religioso no espaço público de sociedades seculares ocidentais. Porém, ele constitui essencialmente uma resposta ao ressurgimento político e cultural do fundamentalismo cristão ao longo dos últimos 40 anos nos Estados Unidos. Isso nos leva a perceber, obviamente, que existe uma grande preocupação por parte de seus atores acerca do papel, das funções e do lugar da religião no âmbito do atual cenário político norte-americano.

Assim sendo, em crítica direta à influência da religião na política, Sam Harris afirma que, muito embora “em comparação com os terrores teocráticos da Europa medieval, ou mesmo em comparação com aqueles que ainda persistem em grande parte do mundo muçulmano, a influência da religião no ocidente agora possa parecer bastante benigna”, ele acredita que não devemos ser enganados por tais comparações, pois em sua opinião “o grau em que as ideias religiosas ainda determinam as políticas governamentais - especialmente nos Estados Unidos - representam um grave perigo a todos” (HARRIS, 2004, p. 153). Além disso, no prefácio de seu livro Letter to a Christian Nation (2006), uma obra em forma de carta dirigida pontualmente à sociedade norte-americana, Harris afirma que, nos Estados Unidos, “os cristãos agora exercem uma extraordinária influência sobre nosso discurso nacional - em nossos tribunais, em nossas escolas, e em todas as esferas do governo”. Por isso mesmo, ele declara que o principal propósito de seu livro é “armar os secularistas de nossa sociedade [a sociedade norteamericana], que acreditam que a religião deva ser mantida fora das políticas públicas, contra seus oponentes na Christian Right” (HARRIS, 2006, p. ix, viii).

Para Sam Harris, são diversos os perigos decorrentes do uso de crenças religiosas como fundamento de políticas governamentais são realmente graves. No caso norte-americano, em particular, o primeiro destacado por esse neoateísta diz respeito às políticas em relação ao Oriente Médio. Na perspectiva de Sam Harris, bem como na dos demais neoateístas, as políticas externas dos Estados Unidos para aquela região estão comprometidas por uma interpretação escatológica da teologia cristã. De acordo com Harris, "por muitos anos a política norteamericana no Oriente Médio tem sido moldada, pelo menos em parte, pelos interesses que os cristãos fundamentalistas têm no futuro de um Estado Judeu”. (HARRIS, 2004, p. 153). 
Por isso mesmo, como o próprio Harris reconhece, não é de se admirar que “o presidente Ronald Reagan interpretava as crises no Oriente Médio através das lentes da profecia bíblica”. E não apenas isso. Esta perspectiva de avaliação permitiu a Reagan incluir homens como Jerry Falwell e Hal Lindsey como participantes de suas instruções dadas ao Conselho de Segurança Nacional (HARRIS, 2004, p. 153). ${ }^{15}$ De fato, na opinião desse neurocientista, bem como na opinião de alguns outros estudiosos do assunto, "os cristãos fundamentalistas tem oferecido apoio a Israel, porque eles acreditam que a consolidação definitiva do poder judaico na Terra Santa - especificamente, a reconstrução do templo de Salomão - vai pavimentar a via tanto para a Segunda Vinda de Cristo quanto a destruição final dos judeus” (HARRIS, 2004, p. 153). Na avaliação desse neoateísta, basta examinar o primeiro apoio internacional para o retorno judaico à Palestina - a Declaração Britânica Balfour de 1917 - para se perceber que ela foi conscientemente inspirada, pelo menos em parte, por uma sintonia com a profecia bíblica. Assim sendo, continua Harris, “estas intromissões da escatologia no âmbito das políticas modernas sugerem que os perigos que a fé religiosa oferece dificilmente podem ser exagerados”. ${ }^{16}$ A conclusão de Harris, então, é que a atual governança dos EUA, isto é sua capacidade de planejar, formular, programar políticas e cumprir funções caiu, de fato, sobre o controle ideológico da Christian Right (HARRIS, 2004, p. 153-154).

Além das políticas norte-americanas em relação ao Oriente Médio, Harris também ataca com suas críticas outro perigo que ele também considera grave: a influência da religião sobre a vida e o governo dos presidentes dos Estados Unidos, bem como sobre a vida e a gestão de outros membros do governo. Como vimos acima, o presidente Ronald Reagan foi alvo de suas críticas. Entretanto, Reagan não constituiu uma exceção em relação à influência da religião sobre a política norte-americana. De fato, a “Casa Branca de Bush”, classificada por Harris como "uma colmeia com grupos de oração e células de estudos bíblicos, semelhante a um monastério esbranquiçado” também foi alvo das críticas desse neoateísta. Referindo-se especificamente a George W. Bush, Harris declara que;

Nosso presidente fala regularmente em frases adequadas para o século XIV, e ninguém parece inclinado a descobrir o que palavras como 'Deus', 'cruzada' e 'poder

\footnotetext{
15 Segundo Johnson, em um jantar em 1971, Reagan teria dito ao legislador da Califórnia James Mills que 'tudo está no lugar para a batalha do Armagedom e para a Segunda Vinda de Cristo’. Além disso, o presidente Reagan teria mesmo permitido Jerry Falwell a participar de suas instruções ao Conselho de Segurança Nacional e convidado Hal Lindsey - autor e defensor da ideia veiculada por Reagan - a ministrar uma palestra sobre segurança nuclear com a Rússia para os principais estrategistas do Pentágono. Cf. JOHNSON, E. Grace Halsell's Prophecy and Politics: Militant Evangelists on the Road to Nuclear War. Journal of Historical Review 7, ${ }^{\circ} 4$ (Winter 1986). ${ }^{16}$ Sobre as relações entre escatologia bíblica e política, ver, por exemplo: GORENBERG, 2000.
} 
milagroso’ significa para ele. Não apenas estamos ainda nos alimentando com vísceras, com as partes podres deixadas pelo mundo antigo, como também estamos positivamente orgulhosos disso (HARRIS, 2004, p. 47).

Além disso, Harris tem sugerido que muitos membros do governo dos Estados Unidos atualmente concebem suas responsabilidades profissionais em termos religiosos. Como exemplos contemporâneos dessa “piedade governamental”, Harris destaca, por um lado, a pertença de proeminentes republicanos ao chamado Conselho de Política Nacional. De acordo com esse neoateísta, esse Conselho é “uma secreta organização cristã de pressão fundado por Tim LaHaye, coautor fundamentalista da apocalíptica série de livros 'Left Behind' (Deixados para Trás), que se reúne trimestralmente para discutir não se sabe o quê”. Segundo Harris, o próprio George Bush, em 1999, fez um discurso a portas fechadas para esse grupo, após o que a Direita Cristã endossou sua candidatura. De fato, como demonstram os dados, $40 \%$ daqueles que, eventualmente, votaram em Bush eram evangélicos brancos (HARRIS, 2004, p. 155). Por outro lado, Harris avalia que "homens ansiosos para fazer a obra do Senhor” foram eleitos para outras esferas do governo federal também. Em especial, o autor destaca o líder da maioria da Câmara, Tom DeLay, que por sua vez apresentou verdadeiras “pérolas” em seus comentários, tais como "somente o cristianismo oferece uma maneira de viver em resposta às realidades que nós encontramos neste mundo. Apenas o cristianismo”. Além disso, ele mesmo alega ter ido para a política “para promover uma cosmovisão bíblica”, critica Harris (2004, p. 156). ${ }^{17}$

Diante de posicionamentos como esse, Harris chega mesmo à conclusão de que estamos próximos de uma teocracia (HARRIS, 2004, p. 157). Em seu entendimento, portanto, apesar da separação explícita entre Igreja e Estado determinada pela Constituição dos Estados Unidos, “o nível de crença religiosa no país (e a importância concomitante da religião para a vida e o discurso político americano) rivaliza com o de muitas teocracias” (HARRIS, 2013, p. 147). E como um lamento declara: “nós vivemos em um país no qual uma pessoa pode não se eleger presidente se ele abertamente dúvida da existência do céu e do inferno” (HARRIS, 2004, p. 39). ${ }^{18}$

\footnotetext{
${ }^{17}$ Sobre a influência religiosa na vida de membros do governo dos Estados Unidos, ver a crítica feita por Krugman, Paul. Gotta Have Faith, New York Times, December 17, 2002. Disponível em: <http://www.nytimes.com/2002/12/17/opinion/gotta-have-faith.html>. Acesso em 23 set. 2015.

${ }^{18}$ Assim como Harris, Dawkins lança suas críticas em relação à discriminação que existe atualmente na esfera pública norte-americana em relação aos agnósticos e aos ateístas. Citando uma das respostas dadas pelo então presidente George Bush (pai) ao repórter Robert Sherman (1988), quando perguntou se ele (Bush) reconhecia a
} 
Outro dado importante a ser destacado na avaliação de Harris em relação ao grau de influência da religião sobre a política norte-americana, diz respeito a sua observação acerca da relação entre filiação partidária e saúde social, ou bem-estar social. Em sua opinião, muito embora a filiação partidária nos Estados Unidos não seja um perfeito indicador de religiosidade, ele afirma que “não é segredo que os ‘estados vermelhos’ são principalmente vermelhos por causa da influência política esmagadora dos cristãos conservadores”. ${ }^{19}$ Assim sendo, em sua opinião, “se houvesse uma forte correlação entre o conservadorismo cristão e a saúde social, poderíamos esperar para ver algum sinal dessa saúde social nos estados vermelhos nos Estados Unidos”. Entretanto, afirma esse autor, “nós não podemos”. (HARRIS, 2006, p. 44). De fato, como observado por ele mesmo, das 25 cidades com as menores taxas de crimes violentos, $62 \%$ estão nos estados ‘azuis’ e 38\% estão nos estados ‘vermelhos’. Das vinte e cinco cidades mais perigosas, 76\% estão nos estados vermelhos, 24\% nos estados azuis. Na verdade, três das cinco cidades mais perigosas dos Estados Unidos estão no piedoso estado do Texas. Os vinte estados com os maiores índices de roubo são vermelhos. Vinte e quatro de vinte e nove estados com os maiores índices de furtos são vermelhos. De vinte e dois estados com os maiores índices de homicídio, dezessete são vermelhos (HARRIS, 2006, p. 45). ${ }^{20}$

A conclusão de Harris, portanto, é que, por um lado, a crença em Deus pode levar à disfunção social (a qual levaria, por sua vez, ao aumento da crença em Deus); e que, por outro lado, a crença generalizada em Deus não garante a saúde ou o bem-estar de uma sociedade. De acordo com esse neoateísta, em quase todas as medições de índice de bem-estar de uma

igualdade de cidadania e patriotismo dos americanos ateus, Bush respondeu: "Não sei se ateus deviam ser considerados cidadãos, nem se deveriam ser considerados patriotas. Esta é uma nação regida por Deus” (Apud: DAWKINS, 2008, p.65). Diante de posições como essas Dawkins critica o fato de que o clima político atual nos Estados Unidos teria "horrorizado Jefferson, Washington, Madison, Adams e todos os seus amigos”. “Tenham sido eles ateus, agnósticos, deístas ou cristãos”, continua Dawkins, eles “teriam recuado alarmados diante dos teocratas da Washington do início do século XXI” (DAWKINS, 2008, p. 67).

${ }^{19}$ A classificação: Estados Vermelhos (Red States) e Estados Azuis (Blue States) aponta uma divisão política entre os Estados Republicanos (Red States) e os Estados Democratas (Blue States). Cf. LEVENDUSKY; POPE, 2011. Disponível em: <http://sites.sas.upenn.edu/mleven/files/redblue_poq.pdf>. Acesso em: 23 set. 2015. Após as eleições os meios de comunicação continuaram a utilizar este esquema de cores para descrever estados republicanos e democratas. Um desses exemplos é o mapa eleitoral apresentada pelo The New York Time em 11 de maio de 2008 acerca da eleição presidencial ocorrida naquele ano nos EUA. Disponível em: <http://politics.nytimes.com/election-guide/2008/electoralmap/index.html>. Acesso em: 23 set. 2015.

${ }^{20}$ Os dados estatísticos apresentados por Sam Harris se baseiam nos dados apresentados por G. S. Paul em "CrossNational Correlations of Quantifiable Societal Health with Popular Religiosity and Secularism in the Prosperous Democracies”, Journal of Religion and Society, vol. 7 (2005), disponível em: <http://moses.creighton.edu/jrs/2005/2005-11.pdf>. Acesso em: 7 dez. 2015; bem como nas informações apresentadas por R. Gledhill, "Societies Worse Off 'When They Have God on Their Side', The Times (U.K.), 27 de setembro de 2005. Disponível em: < http://www.thetimes.co.uk/tto/news/uk/article1938693.ece>. Acesso em: 7 dez. 2015. 
sociedade, os países menos religiosos estão em melhor situação do que a de maioria religiosa. Países como Dinamarca, Suécia, Noruega e Holanda - "que são as sociedades mais ateias da Terra”, afirma Harris,

Estão consistentemente melhor do que as nações religiosas em taxas de expectativa de vida, mortalidade infantil, crimes, alfabetização, Produto Interno Bruto (PIB), bemestar infantil, igualdade econômica, competitividade econômica, igualdade de gênero, saúde pública, investimento em educação, taxas de ingresso na universidade, acesso à internet, proteção ambiental, ausência de corrupção, estabilidade política, apoio as nações mais pobres, etc. (HARRIS, 2013, p. 147).

Isso, em sua opinião, explicaria o fato dos Estados Unidos serem ao mesmo tempo a única entre as democracias ricas em seu nível de aderência religiosa, bem como, ao mesmo tempo, a única exclusivamente assediado pelas altas taxas de homicídio, aborto, gravidez na adolescência, doenças sexualmente transmissíveis e de mortalidade infantil (HARRIS, 2006, p. 44).

Como temos observado, Sam Harris, em particular, tem articulado suas críticas ao que considera uma nociva influência da religião sobre a política dos Estados Unidos, a partir de alguns elementos, amplamente divulgados, que também têm atraído a atenção de outros pesquisadores e estudiosos que se confrontam com lugar da religião no espaço público e no discurso político das sociedades contemporâneas, quer elas sejam democráticas ou não. ${ }^{21}$ Assim sendo, como já mencionamos, principalmente após os atentados terroristas do 11 de Setembro de 2001, a análise sobre a influência - nociva ou não - da religião na definição das políticas públicas tem sido objeto de análises e críticas elaboradas por diversos autores quer sejam eles ateístas ou não.

Como temos observado, durante as últimas décadas os americanos têm se envolvido em um conflito cultural que, como estamos a ver, conforma em muito o discurso político do país neste começo de um novo milênio. Mais uma vez temos, de um lado deste conflito, aqueles que insistem que os Estados Unidos têm sido desde sua concepção uma "nação cristã”, e que em algum lugar ao longo do caminho desviou-se de seu rumo original. Eles culpam os "liberais”, não só por terem virado suas costas para a herança religiosa do país, mas por abertamente atacarem aqueles que abraçam os valores cristãos “tradicionais”. Para apoiar suas reivindicações, esses conservadores muitas vezes entendem que os colonos agricultores - como

${ }^{21}$ Como, por exemplo, ZUCKERMAN, 2008. 
os puritanos da Nova Inglaterra e os anglicanos de Chesapeake - dão início a uma tradição à qual os "pais fundadores”, por sua vez, deram plena continuidade: a missão implantar na América o "verdadeiro" cristianismo e praticá-lo em liberdade. Além disso, os que assim pensam insistem que os autores da constituição de 1787 nunca tiveram a intenção de uma separação entre Igreja e Estado, argumentando que, no máximo, a Primeira Emenda visa impedir o Congresso de favorecer alguma única seita. Em busca do registro histórico, esses partidários procuram ou, mais plausivelmente, inventam um "passado utilizável”, um constructu histórico que justifique suas posições. Assim sendo, ao afirmar, por exemplo, que no início a América era uma nação cristã, eles encobrem o fato que muitos americanos, especialmente os americanos nativos, bem como os afro-americanos, não eram cristãos. Nesse sentido, falham em reconhecer a diferença profunda entre os cristãos, tão profunda ao ponto de em alguns casos se questionar quais grupos de fato eram cristãos (LAMBERT, 2006, p. 5). ${ }^{22}$

Partidários de outro lado do conflito cultural também consultam os fundadores da nação de modo a definir um "passado utilizável” para sua própria causa. Eles também tendem a confundir os dois conjuntos de "progenitores", fazendo de ambos apaixonados campeões de uma liberdade de praticar a verdadeira religião que apenas se caminhou em direção à ampla liberdade de consciência para todos. Eles frequentemente concebem a religião como diálogo estritamente privado entre o indivíduo e Deus. Em sua visão, a luta pela liberdade religiosa sempre foi a de indivíduos que insistem em praticar sua fé de acordo com aquilo que eles consideram que deve ser. Estes liberais contemporâneos esquecem que muitos dos defensores da liberdade religiosa e da separação entre igreja e estado, em meados do século XVIII, eram religiosos que efetivamente lutaram pelo direito de expressar suas crenças publicamente. Nenhum deles insistiu tanto na ideia separar política, governo e religião do que os batistas, cuja experiência na Inglaterra e nas colônias foi a de perseguição por parte do Estado a favor da igreja estabelecida. No entanto, os líderes batistas como Isaac Backus e John Leland lutaram pelo direito a uma forma de adoração pública que muitos dos fundadores racionais, mais tarde, criticariam. ${ }^{23}$ Assim sendo, no centro da guerra de culturas permanece a questão de como conciliar a posição daqueles que querem os EUA como uma nação cristã com a posição dos que a pensam como um paraíso de liberdade religiosa, onde as crenças de uma população

\footnotetext{
22 Sobre essa questão ver, por exemplo, ROBERTSON, 1993; FALWELL, 1980; e BUCHANAN, 1990.

${ }^{23}$ Sobre os líderes batistas Isaac Backus e John Leland ver o capítulo escrito por COKER, Joe L. Isaac Backus and John Leland: Baptist Contributions to Religious Liberty in the Founding Era, no livro editado por HALL; DREISBACH, 2014.
} 
diversificada e pluralista são respeitadas (LAMBERT, 2006, p. 5). Neste cenário encontram-se os neoateísta que, desta feita, querem os Estados Unidos - e se possível o mundo - sem religião. ${ }^{24}$

\section{CONCLUSÃO}

Ao longo deste artigo procuramos demonstrar que a religião nas últimas décadas tem se tornado uma força política, cultural e partidariamente organizada, dentro e fora dos EUA. Paradoxalmente estamos vivendo em um mundo que "saiu da religião" mas que "permanece religioso”, ou seja, num mundo em que a religião se confronta com o paulatino deslocamento de seu ponto de aplicação tradicional: ela não mais opera como matriz da lei e como fundamento exclusivo da autoridade moral e, por conseguinte, como "cimento" das instituições sociopolíticas e culturais. Mas é justamente esse o processo de deslocamento do ponto de aplicação da religião que conforma e radicaliza a atual clivagem no âmbito das elites políticoculturais e religiosas que tem gerado um novo tipo de conflito no espaço público não apenas dos EUA, o qual, por sua vez, tem dado às controvérsias entre neoateístas, conservadores, secularistas e neofundamentalistas cristãos a dimensão de uma "guerra de culturas”. ${ }^{25}$

Diante disso, a conclusão a que chegamos é a de que os movimentos neofundamentalista tanto os religiosos quanto os ideológicos são expressões da busca de redefinição de um fundamento transcendente para estruturação do espaço humano-social diante do “desencantamento do mundo" e do desencantamento dos próprios instrumentos que o

\footnotetext{
${ }^{24}$ É importante observar em consonância com Andrade e Barbosa (2019) que, muito embora o movimento neoateísta faça crítica contundente a influência da religião na política, o mesmo movimento também "rejeita os princípios e valores essenciais da laicidade, uma vez que sustenta a erradicação de todas as expressões religiosas tanto no nível coletivo quanto no individual, além de, consequentemente se mostrar, de modo tácito, intolerante à manutenção do instituto de liberdade religiosa no âmbito das sociedades contemporâneas. Diante de tal posicionamento entendemos que o neoateísmo, antes de ser um movimento exclusivamente anticlerical, se constitui de fato, um movimento antirreligião, o que fere radicalmente os valores essenciais da laicidade" (p. 268269).

${ }^{25}$ De acordo com sociólogo James Hunter, "guerra” ou "conflito cultural” é simplesmente "hostilidade social e política enraizada em diferentes sistemas de entendimento moral. A finalidade às quais tendem essas hostilidades é a dominação de um ethos cultural e moral sobre todos os outros” (HUNTER, 1991, p. 42). Muito embora o conceito de "Guerra de Culturas" tenha sido utilizado incialmente para descrever as linhas de conflitos presentes no espaço público da sociedade estadunidense, esse conceito tem sido utilizado para análise desses mesmos conflitos em outras nações, como, por exemplo, no Brasil, país que tem vivenciado - nos últimos anos com maior veemência - uma verdadeira guerra de culturas no âmbito do debate político-partidário na arena pública. Sobre a "guerra de culturas" no Brasil ver, por exemplo, <https://www1.folha.uol.com.br/ilustrada/2018/10/guerrasculturais-se-acirram-no-brasil-e-quem-vence-e-a-direita-de-bolsonaro.shtml>. Acesso em 25 jul. 2020. $<$ https://www.dw.com/pt-br/a-guerra-das-culturas/a-48931926>. Acesso em 25 jul. 2020. $<$ https://www.lepoint.fr/monde/la-guerre-culturelle-fait-rage-dans-le-bresil-de-bolsonaro-21-07-20192325804_24.php.> Acesso em 25 jul. 2020.
} 
possibilitaram: a ciência, a filosofia, a política e a própria democracia. Em nosso entendimento, tal como o neofundamentalismo religioso, o próprio neoateísmo se constitui não apenas como uma resposta, mas como uma expressão de esforços intelectuais para (re)estabelecer um novo fundamento (transcendente e universal, mas não-religioso) da autoridade moral.

Como pudemos observar, neoateístas por um lado e neofundamentalistas religiosos, por outro, querem se firmar, cada um a seu modo, como detentores daquela que, em seus diferentes entendimentos, seria a única reserva de sentido válida a orientar a vida dos indivíduos e das sociedades. Para isso, como vimos, buscam desqualificar o discurso rival e ao mesmo tempo promover o seu próprio discurso.

As críticas neoateístas sobre a influência da religião no âmbito das sociedades seculares leva-nos a considerar ainda uma questão importante: a aparente contradição entre dois discursos conflitantes. De um lado, teríamos o discurso do neofundamentalismo protestante norte-americano, no qual é reforçada sistematicamente a constatação da perda da influência do cristianismo no âmbito da esfera cultural e política dos EUA e, simultaneamente, é reforçada a retórica do chamamento a uma ação político-partidária pautada por orientações de matriz religiosa. Por outro lado, teríamos o discurso neoateísta - que se configura como um contradiscurso ao neofundamentalismo. Todavia, ele também proporciona uma constatação importante: a do sentimento de perda de eficácia e de autoevidência dos ideais secularistas mesmos diante do retorno significativo da influência religiosa no espaço público e políticopartidário de muitas sociedades seculares. Como vemos, apesar das diferenças significativas entre os discursos (e os atores) há algo em comum entre estes dois discursos polares que requer nossa atenção. Dadas estas diferentes percepções sobre o lugar e o papel da religião no espaço público podemos nos perguntar: estaríamos vivendo um momento pós-cristão, momento-ápice da perda progressiva de eficácia organizadora da religião sobre a totalidade da vida da sociedade, como parecem sugerir as entrelinhas do discurso neofundamentalistas? Ou estaríamos em um singular momento, qualificado por alguns como pós-secular? ${ }^{26}$ Momento de

\footnotetext{
${ }^{26}$ Segundo Gustavo Gilson Oliveira e Aurenéa Maria Oliveira, em artigo publicado na Revista de Teologia e Ciências da Religião da UNICAP/PE, o denominado “pós-secularismo" preconiza a necessidade de um questionamento radical dos próprios postulados epistemológicos e ontológicos das teorias da (des) secularização. O termo "sociedade pós-secular” foi disseminado inicialmente por Habermas (2006, 2005) e por Joas (2008) como descrevendo uma mudança significativa - e democraticamente positiva - na "autocompreensão" do Estado secular e da sociedade atual, sobretudo europeia, no que diz respeito à legitimidade da incidência de forças emanadas da religião no espaço público. A expressão “pós-secularismo”, todavia, pode ser também utilizada em um sentido mais forte, mais próximo da perspectiva assinalada por De Vries (2006), como uma estratégia de problematização
} 
ressignificação tanto do religioso quanto do secular, como parecem sugerir as entrelinhas do discurso dos atores ligados ao movimento neoateísta? Mas, quem sabe, estaríamos vivenciando a coexistência mesma desses dois momentos?

Na avaliação do filósofo francês Marcel Gauchet, o mundo contemporâneo assiste a duas dinâmicas simultâneas e co-constitutivas: um processo em curso de "saída da religião, compreendida como saída da capacidade do religioso em estruturar a política e a sociedade” como um todo, e a um processo de "permanência do religioso na ordem da convicção última dos indivíduos, observando nesse terreno um amplo espectro de variações, segundo as experiências históricas e nacionais muito amplas” (FERRY; GAUCHET, 2004, p. 55).

Entretanto, segundo esse pensador esta permanência da fé com suas revivescências periódicas, não sugere de modo algum, um retorno da religião enquanto instituição englobante e estruturante da totalidade social, tal como foi um dia. Mesmo diante de fenômenos mais pontuais, como no caso da revolução iraniana, em 1970, ou no da emergência do neofundamentalismo cristão nos Estados Unidos, país “que oferece um exemplo único da coexistência de uma sociedade funcionando segundo uma lógica secular e, em muitos aspectos, mais materialista do que qualquer outro lugar e de um povo religioso”, tais retornos não indicam uma recomposição da organização das sociedades com base em uma matriz religioso-política, seja ela teocrática ou teológico-política. Não o indicam mesmo ali onde "as igrejas tornaramse depositárias da identidade nacional devido a motivos históricos”, como na Irlanda, Polônia ou Grécia (GAUCHET, 2008, p. 11-13). Por outro lado, a saída da religião “não significa desaparição de qualquer experiência do tipo religioso”. Muito ao contrário, significa apenas que a religião perdeu "a capacidade de [...] estruturar a política e a sociedade” mais que, todavia, permanece na ordem da convicção dos indivíduos (GAUCHET, 2004, p. 55).

Assim sendo, a levar em consideração as análises de Marcel Gauchet, podemos perceber que as sociedades ocidentais contemporâneas estão presenciando a coexistência de dois momentos que operam simultaneamente. De um lado, um momento “pós-cristão” ou "pósreligião", que pode ser visto como uma etapa de "saída da religião”, ou seja, momento de inflexão da capacidade organizadora do cristianismo e da religião sobre a totalidade da vida

da percepção da persistência atual das religiões através de um questionamento ou “desconstrução” da oposição binária entre religião e modernidade (OLIVEIRA; OLIVEIRA, 2012). Para maiores informações sobre o termo pós-secular, ver também: HABERMAS, 2008; e, STOECKL, 2011. 
social e do significativo esforço para retomá-la. Por outro, uma permanência e até mesmo uma intensificação das crenças religiosas, as quais muito embora possuam um papel social importante, não constituem mais a única reserva de sentido e de fundamentos (morais e até mesmo metafísicos) para os indivíduos e de orientações para o estar-junto coletivo. Desde o momento em que a religião deixa efetivamente de constituir a fonte das fontes organizadoras das instituições sociopolíticas e culturais e de operar como matriz da lei e como fundamento exclusivo da autoridade moral, passamos a vivenciar um definitivo deslocamento do ponto de aplicação da religião em nossas sociedades. Isto não obstante o atual "retorno do religioso", como afirmam uns, ou o "reencantamento do mundo", como desejam outros. Assim sendo, a religião torna-se apenas mais uma reserva de sentido dentre outras a fundamentar as convicções últimas dos indivíduos. É importante ressaltar que processo de intensa clivagem entre as elites político-culturais seja nos Estados Unidos, no Brasil ou em outros países ocidentais decorre justamente deste deslocamento do ponto de aplicação da religião.

\section{REFERÊNCIAS BIBLIOGRÁFICAS}

ALMOND, Gabriel A.; SIVAN, Emmanuel; APPLEBY, R. Scott. Fundamentalisms Genus and Species. In: MARTY, Martin E.; APPLEBY, R. Scott. Fundamentalisms Comprehended. The Fundamentalism Project - Volume 5. Chicago and London: The University of Chicago Press, 1991.

ANDRADE, R. S.; BARBOSA, W. V. Ciência Moderna, Religião e os Novos Ateístas. Curitiba: Appris, 2019.

ARMSTRONG, Karen. Em nome de Deus: o fundamentalismo no judaísmo, no cristianismo e no islamismo. São Paulo: Companhia das Letras, 2009.

BARBOSA, Wilmar do Valle. Relações entre Laicidade e Religião: considerações sobre uma tensão permanente. Numen: Revista de Estudos e Pesquisa da Religião, v. 16, n.1, jan./jun. 2013. Juiz de Fora: Ed. UFJF, 2013, pp. 79-102.

BEATTIE, Tina. The New Atheists: The Twilight of Reason and the War on Religon. London: Orbis Books, 2008.

BENSON, Bruce; HELTZEL, Peter Goodwin (Ed.) Evangelicals and Empire: Christian Alternatives to the Political Status Quo. Michigan: Brazos Press, 2008.

BERGER, Peter. A dessecularização do mundo: uma visão global. Religião e Sociedade, vol. 21, $\mathrm{n}^{\mathrm{o}} 1,2001$. 
. Modernidade, Pluralismo e Crise de Sentido: a orientação do homem moderno. Petrópolis: Vozes, 2004.

BRAECKMAN, Antoon. The Closing of the Civic Mind: Marcel Gauchet on the 'Society of Individuals’. Thesis Eleven, Number 94, August 2008: 29-48. Los Angeles, London, New Delhi and Singapore: SAGE Publications.

BUCHANAN, Patrick J. 1992 Republican National Convention Speech, Houston, Texas, August 17, 1992a. Disponível em: <http://buchanan.org/pa-92-0817-rnc.html>. Acesso em: 04 fev. 2015.

CAYLOR, Bob. Terry Preaches Theocratic Rule "No more Mr. Nice Christian" is the pro-life activist's theme for the '90s. Randall Terry, News Sentinel [Fort Wayne, Indiana], August 16, 1993. Disponível em: <http://www.news-sentinel.com/>. Acesso em 19 jan. 2015. Disponível também em: <http://mediamatters.org/research/2005/03/21/who-is-randall-terry/132921>. Acesso em: 21 ago. 2015.

CARPENTER, Joel A. Fundamentalist Institutions and the Rise of Evangelical Protestantism, 1929-1942. In: MARTY, Martin E. (Ed.) Modern American Protestantism and Its World: Fundamentalism and Evagelicalism. Munich: K. G. Saur, 1993.

COKER, Joe L. Isaac Backus and John Leland: Baptist Contributions to Religious Liberty in the Founding Era, In: HALL. M. D. \& DREISBACH, D. L. Faith and the Founders of the American Republic. Oxford Scholarship, 2014.

DAWKINS, R. Deus, um delírio. São Paulo: Companhia das Letras, 2007.

DECLARATION INTERNATIONALE SU LAÏCITÉ. In: BAUBERÓT, J. L’integrisme republicain contre la laïcité. La Tour des Aigues: De l’Aube, 2006.

DENNETT, D. Quebrando o Encanto: A religião como fenômeno natural. São Paulo Globo 2006.

DOBSON, E.; FALWELL, J.; HINDSON, E. E. The Fundamentalist Phenomenon: The resurgence of conservative Christianity. Ada, Michigan: Baker Publishing Group, $2^{\text {nd }}$ ed., 1986.

FALWELL, Jerry. Listen, America! Garden City, New Jersey: Doubleday and Company, Inc., 1980.

FERRY, Luc; GAUCHET, Marcel. Depois da religião: O que será do homem depois que a religião deixar de ditar a lei? Rio de Janeiro: DIFEL, 2008.

GAUCHET, Marcel. Religião, ética e democracia. Numen: Revista de Estudos e Pesquisa da Religião, v. 16, n.1, jan./jun. 2013. Juiz de Fora: Ed. UFJF, 2013, pp. 15-28.

Madri: Ed. Trotta, 2005.

El desencantamiento del mundo: una historia política de la religión. 
ElCobre Ediciones, 2003.

La religión en la democracia : el camino del lacismo. Barcelona :

GLEDHILL, R. "Societies Worse Off 'When They Have God on Their Side', The Times (U.K.), 27 de setembro de 2005. Disponível em: <

http://www.thetimes.co.uk/tto/news/uk/article1938693.ece>. Acesso em: 7 dez. 2015.

GOLDBERG, Michele. Kingdom Coming: The rise of Christian Nationalism. New York: W.W. Norton, 2006.

GORENBERG, G. The End of Days: Fundamentalism and the Struggle for the Temple Mount. Oxford: Oxford Univ. Press, 2000.

HALEY, C.; DAVIS, C. The Cultural Logic of Evangelical Christianity. In: ROBBINS, Jefrey W.; MAGEE, Neal. The Sleeping Giant has awoken: the new politics religion in the United States. New York: Continuum, 2008.

HANKINS, Barry (Ed.). Evangelicalism and Fundamentalism: A documentary reader. New York University Press, 2008.

HARRIS, S. Carta a uma Nação Cristã. São Paulo: Companhia das Letras, 2008. . Letter to a Christian Nation. New York: Vintage Books, 2006.

. The End of Faith: Religion, Terror, and the Future of Reason. New York: W.W.Norton, 2004.

HART, D. G. That old time religion in modern America: Evangelical Protestantism in the Twentieh century. Chicago: Ed. Ivan R. Dee Publishers, 2002.

HEELAS, Paul; MARTIN, David. Religion, modernity, and postmodernity. Massachusetts: Blackweel Publishers, 1999.

HITCHENS. C. Deus não é grande: como a religião envenena tudo. Rio de Janeiro: Ediouro, 2007. . Thomas Jefferson: Author of America. New York: HarperCollins e-books, 2006.

JOHNSON, E. Grace Halsell's Prophecy and Politics: Militant Evangelists on the Road to Nuclear War. Journal of Historical Review 7, $n^{\circ} 4$ (Winter 1986).

HOOD Jr., Ralf W.; HILL, Peter C.; WILLIAMSON, W. Paul. The Psychology of Religious Fundamentalism. New York: The Guilford Press, 2005.

HUNTER, James. Culture wars: the struggle to define America. New York: Basic Books, 1991.

KENGOR, Paul. God and Ronald Reagan: a spiritual life. New York: Regan Books, 2004. 
LAMBERT, Frank. The Founding Fathers and the Place of Religion in American. Princeton University Press, 2006.

2008.

Religion in American Politics: a short history. Princeton University Press,

LEDEWITZ, Bruce. American Religious Democracy: coming to terms with the end of secular politics. London: Praeger Publishers, 2007.

LEJON, Kjell O. U. Reagan, Religion and Politics: The Revitalization of "a Nation under God” during the 80s. Lund, Sweden: Lund University Press, 1988.

LEVENDUSKY, M. S.; POPE, J. C. Red States vs. Blue States: Going beyond the mean. Public Opinion Quaterly, vol. 75, n² 2, Summer 2011, pp. 227-248.

LINDSEY, Hal. The 1980s: Countdown to Armageddon. Michigan: Grand Rapids, 1980.

LONDON, Hebert. America's Secular Challenge: the rise of a New National Religion. New York: Brief Encounters, 2008.

MARSDEN, George M. Fundamentalism and American Culture: The Shaping of Twentieth-Century Evangelicalism 1870-1925. Oxford: Oxford University Press, 1980 (2a ed. 2006).

Understanting fundamentalism and evangelicalism. Michigan: William B.

Eerdmans Publishing Company, 1991.

PAUL. G. S. Cross-National Correlations of Quantifiable Societal Health with Popular Religiosity and Secularism in the Prosperous Democracies, Journal of Religion and Society, vol. 7 (2005), disponível em: <http://moses.creighton.edu/jrs/2005/2005-11.pdf>. Acesso em: 7 dez. 2015

PEÑA-RUIZ. Henri. A laicidade como princípio fundamental da liberdade espiritual e da igualdade. Madri, 2000. Disponível em: <http://www.laicidade.org/documentacao/textoscriticos-tematicos-e-de-reflexao/a-laicidade-como-principio-fundamental/>. Acesso em: 25 mar. 2013.

Laberinto, 2001.

La emancipación laica: filosofía de laicidade. Madri: Ediciones del

President's Remarks to the Nation, Ellis Island, September 11, 2002. Disponível em: $<$ http://www.whitehouse.gov/news/releases/2002/09/20020911-3.html>. Acesso em: 26 de dez. de 2014.

ROBERTSON, Pat. The Turning Tide: The Fall of Liberalism and the Rise of Common Sense. Dallas: World Publishing, 1993. 
STAHLBERG, Ben. Theocratic America? Christianity and the Structure of Political Discourse. In: ROBBINS, Jefrey W.; MAGEE, Neal (Eds.) The Sleeping Giant has Awoken: the new politics religion in the United States. New York and London: Continuum, 2008.

UTTER, Glenn; STOREY, John. The Religious Right: A Reference Handbook. Santa Barbara, CA, 1995.

WALLIS, JIM. Dangerous Religion: George W. Bush's Theology of Empire. In: BENSON, Bruce; HELTZEL, Peter Goodwin (Eds.) Evangelicals and Empire: Christian Alternatives to the Political Status Quo. Michigan: Brazos Press, 2008.

WEBB, George. The Evolution Controversy in America. Lexington: University of Kentucky Press, 1994.

WILLAIME, Jean-Paul. Religious and Philosophical Diversity as a Challenge for the Secularism: a Belgian-French Comparasion. In: GIORDAN, Giuseppe; PACE, Enzo (Eds.) Religious Pluralism: Framing Religions Diversity in the Contemporary World. New York, London: Springer, 2014. 